\title{
Improving Students' Report Writing Quality in an EAP Context: Group versus Individual
}

\author{
Holi Ibrahim Holi Ali \\ Rustaq College of Applied Sciences, P.O Box 10P.C 329, Rustaq Sultanate, Oman
}

Tel: 96-892-295-223_E-mail: howlli2@yahoo.com

Received: December 10, 2011

Accepted: January 4, 2012

Published: March 1, 2012

doi:10.5539/elt.v5n3p153

URL: http://dx.doi.org/10.5539/elt.v5n3p153

\begin{abstract}
This paper looks into report writing quality on both individual and group bases in an EAP context. A total of 100 EFL students at post foundation level in a University College in Oman, and 15 EFL teachers were selected randomly. Questionnaires were administered to investigate their perceptions and experiences with report writing quality on individual and group bases. The results revealed the majority of teachers and students were in favour of group writing reports, however, most of them believe individual reports have helped students to take charge of their own learning and improve their reports quality. Sample reports were also compared and contrasted, and the results indicated there was that individual reports quality is better than group reports. Recommendations on how report writing quality could be enhanced and improved are presented.
\end{abstract}

Keywords: Report writing quality, Group reports, Individual reports, EAP context

\section{Background}

Report writing involves providing students with an experience and key skills that will powerfully immerse them in practicing academic writing, and will as a result influence their English language proficiency. In Higher College of Technology (HCT), post foundation programme, Oman, reports used to be carried out in groups but since the last semester students have started carrying out their report individually. This change has been received by a mixed feeling from both teachers and students, because this change has put more burdens on them.

The study attempts to compare and contrast reports writing quality and to find EAP teachers' and students' perceptions at the post foundation level in higher college of technology in Oman about individual and group report writing practices. This problem was formulated on the basis of a practical experience in the field that the reports writing of students who study EAP at the post foundation have improved noticeably after they have started writing their reports individually. Although group work could help students to gain many generic skills that they need in their potential work place, however, it was found that some of the students were depending on each other in carrying out their report collectively and at the same time they were getting equal marks which made low achievers depend entirely on the high achievers to get their report done and getting higher marks.

The main objectives of the study are to provide EAP teachers with students' and teachers' beliefs, assumptions and suggestions about the newly implemented approach for report writing within the post foundation department. Also, to examine whether the use of individual report writing approach is useful and has impacted students' reports writing quality positively or not and to find out what kind of improvements appear in individual reports over group ones.

\section{Literature Review}

\subsection{Importance of Group Work in English Language Classroom}

Group is always important for students to learn collaboratively. According to Garvin et al, (1995) cited in Johnston \& Miles (2004) group work frequently included in tertiary education courses, across a wide variety of subject domains such as biology, business studies Freeman, (1995) cited in (ibid:2004), civil engineering Rafiq \& Fulerton, (1996), and computing and information systems, further Lejk et al., (1996). Mello, 1993 and Harvey \& Green, 1994, Yadin \& Or-Bach 2003, Chin \& Overton, 2005 cited in Johnston \& Miles 2004 claimed that group work has a number of learning advantages such as exposing students to other points of views and permitting the development of more comprehensive assignments that are possible for individual based projects, which provide an opportunity for the development of inter-personal and team work skills, such as communication, leadership, planning, time management, skills that are highly sought by employers taking on graduates. However, group projects do raise problems for student evaluation and assessment. For example, assessing a given student's contribution to a group 
into a numeric grade is a complicated task. Debate continues as to whether it is appropriate for a student to obtain higher marks than other group members due to his/ her effort or not. Johnston \& Miles (2004) pointed out that the usual practice in higher education is for students to be graded solely on the quality of a submitted piece of work without the consideration of the effort or input into that product. Therefore, in individual-based projects, however, both the input and the output are determined by the individual and it is easier to be assessed and graded. Moreover, it is difficult for a tutor to adequately assess the contribution of individuals to a group project since much of the work occurs outside formal teaching sessions. A student may receive a high grade despite having very little input into otherwise good group. According to Kruck \& Reif (2001, 37) "some students reported that they are shouldering more than their fair share of the burden for the team's success, while all team members benefit equally from the team's accomplishments". Therefore, teachers strive to evaluate their students fairly but they face the dilemma of including group projects in coursework and being uncertain about finding an accurate way to assess an individual student's contribution to the results achieved by the group. Collaborative projects are effective only if each individual carries his/ her own task and does not rely on the other. However, collaborative work has some problems. Joyce (1999), Morrison (2004) cited in Yadin \& Or-Bach (2006) claimed that one of the biggest problem of collaborative work "free riders" are the students who enjoy the benefits of collaborative work, but don't contribute to the common goal. The students who have not done much are rewarded for the work that they have no done, and those who have worked hard have not been appropriately and adequately acknowledged Kuisma (1999).

\subsection{Challenges in Group Reports Writing in an EFL Context}

Group reports or assignments are considered to be problematic because they involve merging diverse skills and personalities with the hope that they will collaborate towards a common goal Kruck \& Reif, (2001). The first challenge is whether the group project is instructor-assigned or self-selected topics or projects. Whether all the group members are interested in the selected or suggested topics and they are comfortable with it and they can suggest ideas to support their project, whether the group members are to be assigned by the instructor or to be self-selected.

The second challenge in group report occurs when all team members are either not able or not willing to contribute equally to the team's success. Dominating students may inhibit other group members from participating. Members who dominate the group may take on more of the group's work than is appropriate and may not allow other members ample opportunity to participate. This can result in conflict because the team member's contributions are unequal. Yet, they may receive equal marks which might demotivate the students for engaging in group work. The grade earned by students on group work projects do not take into consideration differences in individual contribution and accomplishments.

The final challenge with group report is with conflict and misunderstanding resolution. Tutors sometimes may need to interfere to solve such problems, but such problems prevent the group from becoming non-functional and non-performing. The best method to the group members to solve their own problems without the tutor's interference, this definitely enhances students' teamwork and problem solving skills. Kruck \& Reif, (2001).

\subsection{Individual-based Reports or Assignments}

Individual report is considered to be fair in giving students marks or grades according to what they have achieved, but it lacks collaborative learning and team work skills. The main advantage for this for the tutor is that it reduces the time spent marking individual students scripts. Moreover, this approach helps each student to get a mark based on the quality of his/her project and individual efforts and it helps tutors to personalize feedback that directly related their specific errors they have made to his /her project.

\section{Research Questions}

1. What are the students' and teachers' perceptions about both group/ individual report writing?

2. Did students' reports demonstrate significant improvements when writing their report individually as opposed to collaboratively?

\section{Method}

A questionnaire was administered to 15 teachers and they were chosen on the basis of having the experience of teaching both types of reports individual and group, and 100 students who were chosen randomly from technical communication students'. These students were chosen because they have had the experience of writing both individual-based and group-based reports. The questionnaires follow Linkert-3 point scale. The participants were Omani EFL learners, who had similar cultural, educational and linguistic back grounds at the college level. Besides, 20 reports were chosen from both individual-based and group-based reports and they were compared and contrasted to highlight their differences improvement so as to answer the study questions. The reports were chosen randomly 
from different sections. The data was analyzed mainly quantitatively and frequencies and percentages were used for statistic analysis. The results were tabulated ad presented against the study questions.

\subsection{Discussion and Limitations}

\subsubsection{Analysis of Teachers' Questionnaire (Table 1)}

These results are subject to several limitations. The study doesn't investigate the effects of other factors and variables that could influence the report quality such as the quality of instruction, input from core subjects, students' previous knowledge about report writing, etc. it rather gives a general survey of both teachers' and students' perceptions about individual report writing versus group report writing and their effects on improving report writing quality. Moreover, the number of the participants is only hundred students who are studying Technical Communication, and 15 teachers, which might not be a representative sample of the whole population and which might impede generalization of the study. Moreover, the external validity of this study may be limited and the number of reports was only 20 which might not be a representative sample for both individual and group reports.

Table 1, displayed teachers' responses with regard to the approach used in report writing by the students and their views about both individual and group approaches. In response to question 1 whether students perform better when they write independently rather than in groups, 6 teachers $(40 \%)$ agreed, 3 teachers $(20 \%)$ responded by undecided, and 6 teachers $(40 \%)$ disagreed as they believed that their students didn't perform better when they write their reports individually.

As for question 2, whether individual writing quality has improved noticeably over group reports, only 4 teachers (27\%) teachers 'agreed', 2 teachers (13\%) were 'undecided' $(7 \%)$ so 9 teachers $(60 \%)$ 'disagreed' and they believed that report writing quality hasn't improved any more. It is very clear that the majority of teachers don't like the idea of individual reports writing.

Regarding question 3, whether group work has impacted report writing quality or not, 9 teachers (60\%) 'agreed', 3 teachers (20) weren't sure and 2 teachers (13\%) 'disagreed'. Therefore, it is quite clear that most of the teachers are in favor of group report approach (60\%) and they didn't like the individual report approach. This analysis revealed that the majority of the students were in favour of group reports. This result is significant as it accords with what teachers believed observed about group reports.

As for question 4, regarding the efficiency of individual report approach in giving feedback to students, 6 teachers (40) claimed that individual report helped the teachers to give feedback to their students, $4(27 \%)$ teachers responded by 'undecided', and 5 teachers (33\%) 'disagreed'. Concerning question 5, whether individual reports helped students to write independently, 10 teachers $(67 \%)$ 'agreed', $3(20 \%)$ teachers responded by 'undecided', only 1 teacher (7\%) 'disagreed'. As for question 6, whether individual report has improved students' reports accuracy, layout, consistency or not, only 5 teachers (33\%) 'agreed', 3 teachers $(20 \%)$ responded by 'undecided', 7 teachers (47\%) 'disagreed', so they believed that individual report hasn't improved students' report writing quality any more. Regarding question 7 , whether individual work offered opportunities for students to improve their report writing skills or not, 8 teachers (53) 'agreed', only 1 teacher (4\%) responded by 'undecided', 4 teachers (27\%) 'disagreed'. Therefore, it is quite clear that vast majority of teachers 'agreed' that individual report offers opportunities for students to improve their report writing skills. In response to question 8, whether group work has a negative impact on students' report writing quality or not, 3 teachers (20\%) 'agreed', only 4 teachers $(27 \%)$ reported by 'undecided', 9 teachers $(60 \%)$ 'disagreed'. Concerning question 9 , whether individual report writing has helped students to improve their presentations skills or not, 4 (27\%) 'agreed', only 2 teachers responded by 'undecided', 8 teachers (53\%) 'disagreed'. As for question 10, whether individual report writing has put more burdens on both teachers and students or not, 11 teachers (73\%) 'agreed', only 1 teacher responded by 'undecided', 2 teachers (13\%) 'disagreed'.

In the light of the above discussion and the study questions, the vast majority of teachers are in favor group report writing approach and they believe that it is useful and practical for the both students and teachers. However, a considerable number of teachers agreed that individual report could help students to develop their writing and research skills but it does not reinforce or foster team-working skills. Therefore, they strongly believe that it would be useful for both teachers and students to go for group reports because they help the students to learn many generic skills that are highly demanded in the labour market.

\subsubsection{Analysis of Students' Questionnaire (Table 2)}

Concerning students' responses to question 1, 70 students (70\%) agreed that individual report has given them an opportunity to write independently, 11 students (11\%) responded by undecided, and only 19 students (19\%) disagreed. Thus, it clear that the majority of the students believed that individual report writing has helped them to 
write independently. As for question 2, 67 students agreed, and 20 students $(20 \%)$ responded by undecided and 15 students (15\%) disagreed. Regarding question 3, 71 students' $(71 \%)$ claimed that individual report writing has helped them to take charge of their own writing and learning, 11 students $(11 \%)$ responded by undecided, and 15 students disagreed. As for question 4, 68 students (68\%) agreed that individual reports have helped them to receive feedback from their teachers, 24 students $(24 \%)$ responded by undecided, and 13 teachers (13\%) disagreed. Regarding question 5, 56 students (56\%) agreed that group reports have helped them to get more marks than individual reports, 19 students (19\%) undecided, and 26 students $(26 \%)$ disagreed. Therefore, it is quite clear that most of the students claimed that group reports have given them an opportunity to get higher marks, 26 students (26\%) disagreed.

In response to question 6, 44 students (44\%) claimed that their individual reports quality was better than their group ones, $16(16 \%)$ were undecided, and 42 disagreed. As for question 7, 77 students (77\%) believed that individual report has given them an opportunity to improve their report writing skills, 17 of students (17\%) responded by "undecided" and 16 disagreed. As for question 8, 49 of students (49\%) agreed that group reports have made them rely on their colleagues to get their reports done, 21 of students $(21 \%)$ responded by undecided, and 28 students (28\%) disagreed. Regarding question 9, 65 of the students (65\%) claimed that group report writing has improved their reports' layout, accuracy, consistency, marks, etc. 19 of students (19\%) responded by undecided and 17 students disagreed. It is very clear that the majority of the students believed that group report is useful and it has helped them to improve their reports more than individual reports. As for question 10, 57 of students $(57 \%)$ agreed that individual report writing has made them learn how to write their report independently, 19 students (19\%) reported by undecided, and only 11 students (11\%) disagreed.

In light of the above discussion, most of the students prefer individual reports which have helped them to learn independently and improve their report writing skills, however, it the same time they believe that group reports have also given them the chance to get good marks and to improve their writing skills as well.

\subsection{Differences Appear in the Two Types of Students'Reports: Process and Product}

One of the main learning outcomes of report writing is to help students to master the process which is related to how a report is structured and laid out and the product which is the final outcome of the report such as content, findings, referencing, etc.

Having giving out questionnaires to both teachers and students may not answer the questions raised by the study. Therefore, a total number 20 reports (10 individual-based and 10 group-based) were chosen randomly from different sections. They were compared and contrasted against the newly implemented report marking rubric which contains content, organization, language, images and references. Individual reports contents vary from one to another but generally speaking, they are somewhat focused and they mostly follow the prescribed format (e.g. font size \& type), the use of references is relatively accurate following the prescribed types of resources and format. The images, graphs and illustrations are mostly accurate representation of numerical data. Further, most of the parts of the report were included in order such as the cover page, table of contents, introduction, and research questions, etc. Undoubtedly, this is not because they have been done individually, but there are many factors that could affect the quality of the reports such as the students were give a sample report to follow and a total of four hours of input were devoted to teaching report writing skills, referencing, quotation and paraphrasing skills etc. all these factors could affect the final outcome of the reports and unfortunately all these variables are beyond the scope of this small scale study.

Concerning group reports, the format and organization are relatively inadequate comparable to individual reports according to the sample being investigated and contrasted. References are not cited in the prescribed format and they were mostly relied on the internet and other electronic sources to write their reports. As for format they slightly lack consistency within format such as font size and type, colours and decorations were widely used.

To sum, it is difficult to conclude there were improvements in individual-based report quality because of one or certain factor (s) and variables but it might be due to many factors which are beyond the scope of the study.

\section{Conclusion and Recommendations}

The importance of group work or projects is evidenced by the drive for tertiary institutions to incorporate team-working skills into their visions and missions and in their study programmes. In this study, such drive is realized in group report writing that undoubtedly facilitates learning team-working skills. From this survey analysis, we can conclude that both students and teachers appreciated individual report and its impact on learning but they are in favor of group reports. However, the samples investigated have shown that individual reports are more accurate and better than group reports. 
In the light of the study findings, the following recommendations are made based on the study results, however, these findings and results must be treated with caution. Because they are subject to several limitations such as the study doesn't investigate other variables which could affect this result.

- $\quad$ Teachers should reconsider their assessment and mechanism approaches if group -based approach is used so as to reward their students in a fair way based on what they have done.

- If group -based is used the number of the group members should be reconsidered to make use of group work in more a productive and useful way.

- $\quad$ Group-bases reports should be adopted because the fast majority of teachers and students are in favor of them according to the study findings.

\section{References}

Chin, P., \& Overton, T. (2005). Assessing group work. Primer 6, version, issue, March 2005

Johnston, L., \& Miles, L. (2004). Assessing contribution to group assignments. Assessment \& Evaluation in Higher Education Journal, Vol.29, No. 6, December, 2004

Kruck, S. E., \& Reif, H. L. (2001). Assessing individual student performance in collaborative projects: A case study. Information Technology, Learning, and Performance Journal, Vol. 19, 22, Fall 2011

Kuisma, R. (ND). Assessing individual contribution to a group project. [Online] Available: http://teaching.polyu.edu.hk/datafiles/R46.pdf.htm (November 18, 2011)

Yadin, A., \& Or-Bach, R. (ND). The importance of emphasizing individual learning in the collaborative learning era. Journal of Information Systems, Vol. 21(2). [Online] Available: http://jise.org/Issues/21/vol21-2-pg185.pdf.htm (October 13, 2011)

Table 1. The analysis of teachers' questionnaire

\begin{tabular}{|c|l|c|c|c|c|c|c|}
\hline No & \multicolumn{1}{|c|}{ Statements } & \multicolumn{2}{|c|}{ Agree } & \multicolumn{2}{c|}{ Undecided } & \multicolumn{2}{|c|}{ Disagree } \\
\cline { 3 - 8 } & & $\mathbf{F}$ & $\mathbf{\%}$ & $\mathbf{F}$ & $\mathbf{\%}$ & $\mathbf{F}$ & $\mathbf{\%}$ \\
\hline $\mathbf{1 .}$ & $\begin{array}{l}\text { My students perform better when they write their } \\
\text { report individually. }\end{array}$ & 6 & $40 \%$ & 3 & $20 \%$ & 6 & $40 \%$ \\
\hline $\mathbf{2 .}$ & $\begin{array}{l}\text { Individual report writing quality has improved } \\
\text { noticeably over group writing. }\end{array}$ & 4 & $27 \%$ & 2 & $13 \%$ & 9 & $60 \%$ \\
\hline $\mathbf{3 .}$ & $\begin{array}{l}\text { Group work has a positive impact on students' } \\
\text { report writing quality. }\end{array}$ & 9 & $60 \%$ & 3 & $20 \%$ & 2 & $13 \%$ \\
\hline $\mathbf{4 .}$ & $\begin{array}{l}\text { Individual work has helped me give feedback to my } \\
\text { students more efficiently. }\end{array}$ & 6 & $40 \%$ & 4 & $27 \%$ & 5 & $33 \%$ \\
\hline $\mathbf{5 .}$ & $\begin{array}{l}\text { Individual report writing helps students to learn } \\
\text { how to write independently. }\end{array}$ & 10 & $67 \%$ & 3 & $20 \%$ & 1 & $\mathbf{7 \%}$ \\
\hline $\mathbf{6 .}$ & $\begin{array}{l}\text { Individual report has improved my students' reports } \\
\text { accuracy, layout, consistency, etc. }\end{array}$ & 5 & $33 \%$ & 3 & $20 \%$ & 7 & $47 \%$ \\
\hline $\mathbf{7 .}$ & $\begin{array}{l}\text { Individual work offers opportunities for students to } \\
\text { improve their report writing skills. }\end{array}$ & 8 & $53 \%$ & 1 & $7 \%$ & 4 & $27 \%$ \\
\hline $\mathbf{8 .}$ & $\begin{array}{l}\text { Group work has a negative impact on students' } \\
\text { report writing quality. }\end{array}$ & 3 & $20 \%$ & 4 & $27 \%$ & 9 & $60 \%$ \\
\hline $\mathbf{9 .}$ & $\begin{array}{l}\text { My students' research and presentation skills have } \\
\text { improved drastically when they started writing their } \\
\text { reports individually. }\end{array}$ & 4 & $27 \%$ & 2 & $13 \%$ & 8 & $53 \%$ \\
\hline $\mathbf{1 0}$ & $\begin{array}{l}\text { Individual report writing has put more burdens on } \\
\text { teachers and students as well. }\end{array}$ & 11 & $73 \%$ & 1 & $\mathbf{7 \%}$ & 2 & $\mathbf{1 3 \%}$ \\
\hline
\end{tabular}


Table 2. The analysis of Students' Questionnaire

\begin{tabular}{|c|l|c|c|c|c|c|c|}
\hline \multirow{2}{*}{ No } & \multicolumn{1}{|c|}{ Statements } & \multicolumn{2}{|c|}{ Agree } & \multicolumn{2}{c|}{ Undecided } & \multicolumn{2}{|c|}{ Disagree } \\
\cline { 4 - 8 } & & $\mathbf{F}$ & $\mathbf{\%}$ & $\mathbf{F}$ & $\mathbf{\%}$ & $\mathbf{F}$ & $\%$ \\
\hline $\mathbf{1 .}$ & $\begin{array}{l}\text { Individual report writing has given me an opportunity } \\
\text { to write independently. }\end{array}$ & 70 & $70 \%$ & 11 & $11 \%$ & 19 & $19 \%$ \\
\hline $\mathbf{2 .}$ & $\begin{array}{l}\text { Individual report writing has helped to express my } \\
\text { ideas more confidently. }\end{array}$ & 67 & $67 \%$ & 20 & $20 \%$ & 15 & $15 \%$ \\
\hline $\mathbf{3 .}$ & $\begin{array}{l}\text { Individual report writing has made more responsible } \\
\text { of my writing and learning. }\end{array}$ & 71 & $71 \%$ & 11 & $11 \%$ & 15 & $15 \%$ \\
\hline $\mathbf{4 .}$ & $\begin{array}{l}\text { Individual work has helped me receive feedback from } \\
\text { my teachers more efficiently. }\end{array}$ & 68 & $68 \%$ & 24 & $24 \%$ & 13 & $13 \%$ \\
\hline $\mathbf{5 .}$ & $\begin{array}{l}\text { Group report writing has helped me to get good marks } \\
\text { than individual report. }\end{array}$ & 35 & $35 \%$ & 19 & $19 \%$ & 26 & $26 \%$ \\
\hline $\mathbf{6 .}$ & $\begin{array}{l}\text { My individual report writing quality is better than } \\
\text { group writing report quality. }\end{array}$ & 44 & $44 \%$ & 16 & $16 \%$ & 42 & $42 \%$ \\
\hline $\mathbf{7 .}$ & $\begin{array}{l}\text { Group work offers opportunities to improve students' } \\
\text { report writing skills. }\end{array}$ & 77 & $77 \%$ & 17 & $17 \%$ & 16 & $16 \%$ \\
\hline $\mathbf{8 .}$ & $\begin{array}{l}\text { Group work has made me depend on my colleagues to } \\
\text { get my report done. }\end{array}$ & 49 & $49 \%$ & 21 & $21 \%$ & 28 & $28 \%$ \\
\hline $\mathbf{9 .}$ & $\begin{array}{l}\text { Group report writing has improved my report's layout, } \\
\text { accuracy, consistency, marks, etc. }\end{array}$ & 65 & $65 \%$ & 19 & $19 \%$ & 17 & $17 \%$ \\
\hline $\mathbf{1 0}$ & $\begin{array}{l}\text { Individual report writing has made me learn how to } \\
\text { write my report independently. }\end{array}$ & 57 & $57 \%$ & 19 & $19 \%$ & 11 & $11 \%$ \\
\hline
\end{tabular}

\section{Appendix}

\section{Students' Comments}

1. "I prefer more to do the report in group, so it won't be that much difficult. And everyone will know what he/she should do, also it going to improve our skills."

2. "I prefer to write in group because of saving time. Also, concentrate on other subjects; otherwise we can't submit our reports on time".

3. "Individual report makes our minds fresh because it gives us new information, but I think sometimes do by group is better for us it gives us time for other subjects."

4. "Individual report writing is better that the group report."

5. "Just for presentation I think it is better when we do it in a group."

6. "I am with individual report if the group is not helpful but if the group is helpful I am with group report."

7. "It is good to work independently, but I think group work may let us do something larger."

8. "In group report a teacher should know what everyone is going to do in the report".

9. "Individual report writing may also give me more confidence in writing my point of view".

10. "We need group to make reports. I can't do the report alone".

11. "Individual report needs much time to finish, while group report reduces time because of sharing duties between individuals".

12. "Individual report sometimes shows ability of the student in writing report and organizes it as he or she wants, expressing his or her ideas in a well manner."

13. "Group report writing gives an opportunity to give more intelligent ideas".

14. "Individual report is better than group report. Also, in individual report you can improve marks. I hope all the semester to be individual report". 
15. "Individual report better than group. If wanted a group report, members should be less than 4 students."

16. "Writing group report as group team is better than individual report just to save time".

17. "Let us choose our own topic, let us be more creative."

18. "We should work as a one group in our college to learn how to work in a team that's not there in our college".

19. "Individual report writing has spent a lot of time to write and we have 6 subjects so it is difficult."

20. "It's better if we do my report individually, because if we did our work very well. It's better for the future."

21. "Better to write the report with group".

22. "I hope to work with group because we have many subjects and we have many reports in business and this will affect subjects."

23. "Group report is better than individual report".

24. Individual report takes long time until finishing, and always individual report should be given in limited time".

25. "I prefer to write group report because it's more simple".

26. "Group work is best way to write report because it shares the information between students."

27. "Group work is better than individual."

28. "I think individual report helps us more than group report. I think we will get more marks".

29. "Individual report has more benefits to students in their future. But group report we can do it more quickly."

30. "Group report writing is a good way to learn how to make anything with group and work is faster to finish."

31. "We have to give as more time to complete the report because we have many subjects to study. Thanks a lot."

32. I wish the department change the topics of the report and allow students to choose whatever topic in their mind."

33. "Work with group help us to learn better."

34. "Department enters good things for students but this individual report will make students more busy rather than looking after other specializations.

\section{Teachers' Comments}

1. "One topic given for 30 students to cover all aspects is physically impossible. It affects the quality of students' report writing and they find it difficult to get information. Even its busy job for the teachers".

2. "I am in favor of scrapping 'report' writing and replacing it with a less ambitious writing assignment (300 words approx).

3. "Students learning from each other are not taking place when they write their own reports. They can't learn cooperating with other, sharing, promising responsibilities among themselves. They seem to be last doing individual reports."

4. "It depends upon the numbers of students in each section."

5. "Group reports lead to team spirit work and cooperation among students. They practice writing skills together in a competitive atmosphere. I'm personally with teams work though it has some negative sides."

6. "I'm in favor of group report but limit the number to 2 members".

7. "Individual reports deprive the students of the opportunity of sharing, group work and chances of correcting or being corrected by peers." 